\section{$\checkmark$ The Maryland Institutional Ethics Committee Resource Network}

\section{DIANE E. HOFFMANN}

The Maryland Institutional Ethics Committee Resource Network was established in July 1991 as part of the Law and Health Care Program at the University of Maryland School of Law. The purpose of the Network is to assist hospitals and nursing homes in Maryland, which are required by state law to have an ethics committee, in the establishment and functioning of those committees. That purpose will be accomplished by developing educational materials; establishing a series of educational workshops, a network, and a newsletter for ethics committee members; and by conducting research on ethics committee operations. The Network's Advisory ory Committee includes representatives from the following organizations: American Nurses Association, American Asociation of Homes for the Aged, Health Facilities Association of Maryland, Maryland Association of Non-Profit Homes for the Aged; Maryland Disability Law Center, Maryland Hospital Association; Maryland Nurses Association; Medical and Chirurgical Society of Maryland; and the Maryland Society of Hospital Social Work Directors.

The Network sponsored its first educational conference on 28 October 1991 on Implementing the Patient Self-Determination Act: Questions and Answers. In conjunction with the conference, the Network developed a slide show to be used by institutions in Maryland to explain the Patient Self-Determination Act and relevant Maryland law to staff, patients and members of the community.

\section{$\checkmark$ The Florida Bioethics Network}

\section{RAY MOSELEY}

Florida now has a statewide Bioethics Network. The Florida Bioethics Network (FBN) was established in April 1991 at an annual ethics committee retreat and educational program of the Shands Hospital Ethics Committee at the University of Florida in Gainesville. Part of this program was to explore the need for an ethics committee network in Florida. To this end, an invitation was sent to the 100 largest hospitals in Florida to see if other hospitals shared this interest. Over 40 representatives from 21 hospitals attended, and there was unanimous agreement that the Florida Bioethics Network should be formed. An ad hoc committee was appointed to develop a mission and structure for the FBN.

A follow-up survey of every hospital in Florida indicated widespread interest in and need for a statewide network of individuals who participate in hospital ethics committees. (The results of this survey will be reported in depth in a following journal issue.) Many responses requested assistance and/or information about how to institute and run an ethics committee.

The second annual meeting of the FBN on 4 December 1991 was cosponsored by Tampa General Hospital. All hospitals in Florida were invited to send representatives. This meeting was attended by 83 individuals representing 41 Florida hospitals. Another 37 individuals from 11 institutions, who were unable to send representatives to the meeting, expressed interest in joining the FBN.

At this meeting, the mission and objectives of the FBN were discussed and agreed upon. By-laws were ratified, 